\title{
Damage evaluation of ultra-high performance concrete columns after blast loads
}

\section{Jun Li and Chengqing Wu}

\begin{abstract}
As emerging advanced construction material, ultra-high performance concretes have seen increasing field applications over the past two decades to take advantages of their ultra-high mechanical strength and durability; yet the systematic study on its dynamic behaviour under impact and blast loads is not commonly seen. This article presents an experimental and numerical study on the static and dynamic behaviour of an existing ultra-high performance concrete material. Experimental study on its flexural behaviour under static loads is conducted and an inverse study is carried out to derive its uniaxial tensile constitutive law. The derived relationship is used in the material model in hydro-code LS-DYNA together with dynamic material properties to study ultra-high performance concrete columns under blast loads. The residual loading capacity of the column is studied and pressure-impulse diagrams for assessing the ultra-high performance concrete column damage under blast loads are proposed. Parametric study on effects of ultra-high performance concrete strength, column height, cross-section size and reinforcement ratio is performed and analytical equations are proposed for generating pressure-impulse diagrams for generic ultra-high performance concrete columns.
\end{abstract}

\section{Keywords}

Blast load, ultra-high performance concrete column, pressure-impulse diagram, damage evaluation, residual strength

\section{Introduction}

Ultra-high performance concretes (UHPCs) are cementitious material consisting of cement, sand, silica fume, silica flour, superplasticizer and water. With high packing density, UHPCs are equipped with unconfined compressive strength that easily exceeds $150 \mathrm{MPa}$. Due to the elimination of the coarse aggregate, UHPC usually fails in a brittle mode under compression and tension. Fibre reinforcement is a common and effective way to enhance the post-crack material ductility. Until now, several ultra-high performance fibre-reinforced concrete (UHPFRC) products became available on the market such as Ductal, Cemtec, Ceracem, Cardifrc, SIFCON. UHPC can be obtained by

School of Civil and Environmental Engineering, University of Technology Sydney, Sydney, NSW, Australia

\section{Corresponding author:}

Jun Li, School of Civil and Environmental Engineering, University of Technology Sydney, PO Box I23, Broadway, Sydney, NSW 2007, Australia.

Email: Jun.Li-2@uts.edu.au 
first optimizing the matrix strength and packing density, then using very high strength steel fibres with sufficient ductility and then improving the interfacial bonding between the fibre and the surrounding matrix.

Among others, tailoring the fibre content (Wille et al., 2011; Yoo et al., 2013) and improving the interfacial bonding between fibre and surrounding matrix (Stengel, 2009; Wille and Naaman, 2013) are the two most convincing methods for improving the material tensile performance. The superior tensile performance including tensile strength and strain capacity makes UHPC very attractive for use in civil engineering, especially in protective structures against dynamic loads.

Published research on the performance of UHPC against blast loads is quite limited despite its importance. Under blast loads, UHPC containing steel fibres produced very high blast resistance by reducing the maximum displacement, enhancing the damage tolerance and eliminating secondary blast fragments. The blast behaviour of panel components made of Ductal, a commercial UHPC, has been investigated in a number of studies. Ngo et al. (2007) tested seven $2 \mathrm{~m} \times 1 \mathrm{~m}$ Ductal panels having thicknesses which varied between 50 and $100 \mathrm{~mm}$, under live explosives at stand-off distances of 30-50 m and varying charge weights which resulted in reflected pressures of 400-2000 kPa. Overall, the UHPC panels showed high ductility, limited permanent deformations and an ability to absorb substantial energy without fragmentation, in contrast to a companion panel constructed with conventional concrete. Wu et al. (2009) tested a series of Ductal panels having dimensions of $2 \mathrm{~m} \times 1 \mathrm{~m} \times 0.1 \mathrm{~m}$ under 'close-in' blast loads. The one-way panels were partially fixed and exposed to $1-20 \mathrm{~kg}$ of equivalent Trinitrotoluene (TNT) at stand-offs of $1-3 \mathrm{~m}$. The UHPC panels showed increased hinge rotation capacity and an ability to sustain larger blast loads when compared to companion panels made of conventional reinforced concrete. Ellis et al. (2014) tested four simply supported, unreinforced, one-way UHPC panels having dimensions of $1.625 \mathrm{~m} \times 0.864 \mathrm{~m} \times 0.051 \mathrm{~m}$ under reflected impulse loads which varied between 0.77 and 2.05 MPams using a shock-tube. The study determined that the unreinforced panels failed at reflected impulse in between 0.97 and $1.47 \mathrm{MPa}$. The results were used to develop a hierarchical multi-scale model which was then used to conduct a parametric study, demonstrating the factors that increase energy dissipation, such as fibre geometry, fibre packing and fibre volume fraction, are critical to enhance the blast performance of unreinforced UHPC panels. Yi et al. (2012) conducted 'close-in' live explosive tests on three two-way panels constructed with normal strength concrete (NSC), high strength concrete (HSC) and a proprietary UHPC. The $1 \mathrm{~m} \times 1 \mathrm{~m} \times 150 \mathrm{~mm}$ panels were clamped on all four sides and tested under charge weights of 4-16 kg of ammonium nitrate/fuel oil (ANFO) at a stand-off of $1.5 \mathrm{~m}$. When compared to the companion specimens made of HSC and NSC, the UHPFRC panel showed improved blast performance, reduced the maximum and residual displacements, more controlled cracking, with reduced spalling. In a more recent study, the authors investigated the UHPC slabs under $0.1-1 \mathrm{~kg}$ TNT contact detonation and the associated fragmentation based on field blast tests ( $\mathrm{Li}$ et al., 2015, 2016). In summary, research confirms improved performance of UHPFRC under extreme blast loading; however, published research on the performance of structural components is limited, and there is a need for further data, particularly in the case of columns.

Published research on the performance of UHPC columns is even more limited due to the difficulty in testing set-up and axial load modelling. Aoude et al. (2015) tested UHPC columns under simulated blast loads. Nine full-scale columns constructed with compact-reinforced composite (CRC), a proprietary UHPC, were tested under simulated blast loading and exposed to varying blast pressure-impulse (P-I) combinations using a shock-tube. While the fibre and steel reinforcement played an important role in column performance, UHPC is found to significantly improve the column blast resistance and damage tolerance. Published research data on the blast performance of UHPC structural components is focusing primarily on one-way panel components. 
Table I. Mix proportion of UHPC $\left(\mathrm{kg} / \mathrm{m}^{3}\right)$.

\begin{tabular}{llllllll}
\hline Cement & Silica fume & Silica flour & River sand & Superplasticizer & Water & Nanoparticles $\mathrm{CaCO}_{3}$ & $\mathrm{TF}_{\text {fibre }}$ \\
\hline 750 & 225 & 190 & 1030 & 16 & 190 & 21.7 & 191 \\
\hline
\end{tabular}

TF: twisted fibre.

In a recent study, a UHPC material that incorporates nanoparticles was developed (Su et al., 2017), and systematic study on its static and dynamic performance was carried out (Su et al. 2016a, 2016b). Field tests on UHPC columns have demonstrated that such material is highly blast resistant (Xu et al., 2016). In the present study, numerical models that incorporate the static and dynamic material properties of the UHPC material are established in commercial hydro-code LS-DYNA. The tensile damage behaviour of numerical model is validated by the flexural bending tests after inverse analysis on four-point bending tests (FPBTs) is conducted. The numerical models are then used to conduct parametric studies to generate the P-I diagrams for assessing the damage of UHPC columns against blast loads.

\section{Material composition and characteristics}

The main properties of materials used in producing UHPC in this study are presented in the following (Table 1). The cement used was Type sulphate-resisting (SR) cement (namely 42.5 Grade) conforming to Chinese standard GB175-2007 (Shi et al., 2008).

Steel fibre material, that is, twisted fibre (TF) was mixed at a volume dosage of $2.5 \%$ to provide additional tensile and crack resistance. TF has $0.3 \mathrm{~mm}$ diameter and $30 \mathrm{~mm}$ length and its tensile strength is $1500 \mathrm{MPa}$.

Concrete mixtures were prepared in a laboratory concrete mixer. Cubic specimens with dimension of $100 \mathrm{~mm} \times 100 \mathrm{~mm} \times 100 \mathrm{~mm}$ were made for uniaxial compressive tests. After being cured in the humid room at a temperature of $20 \pm 5^{\circ} \mathrm{C}$ for $24 \mathrm{~h}$, the specimens were demolded and then cured in hot water at a temperature of $90^{\circ} \mathrm{C}$ for $48 \mathrm{~h}$. Then the specimens were cured in the first curing room again until they were tested. Both surfaces of the samples were properly levelled, sanded, polished, cleaned and dried to attain smooth surfaces before testing.

In concrete compressive testing, all specimens were loaded via the hydraulically controlled machine at constant loading rate $(0.2 \mathrm{~mm} / \mathrm{min})$ until failure. Two parallel linear variable displacement transducer (LVDTs) were installed to measure the cross-head movement of the testing machine as shown in Figure 1.

Compressive strain measurement under uniaxial compression is difficult for UHPC material. Conventional method using electrical strain gauge is effective in measuring the static modulus of elasticity of UHPC, while it is unable to capture the post-cracking behaviour of the UHPC specimens because the strain gauges are normally detached from the surface and came off at peak strength due to concrete spalling. The second method, that is, in compliance with ASTM C469, uses two rigid circular rings, which are secured at approximately two thirds the height of the specimen using clamping screws. Two LVDTs are introduced between the rings and positioned on opposite sides of the specimen. This method is also good at measuring the modulus and peak strength of UHPC specimens; however, this method is not suitable for capturing the post-peak softening branch because the clamping screws may rotate as the shear line failure occurs after peak (Hassan, 2012). The present test configuration is able to capture the peak strength and post-peak behaviour of the specimens; however, cross-head displacement measurement does not eliminate the platen restraints from the testing machine, which leads to higher strain measurement and smaller value of the initial elastic modulus. 


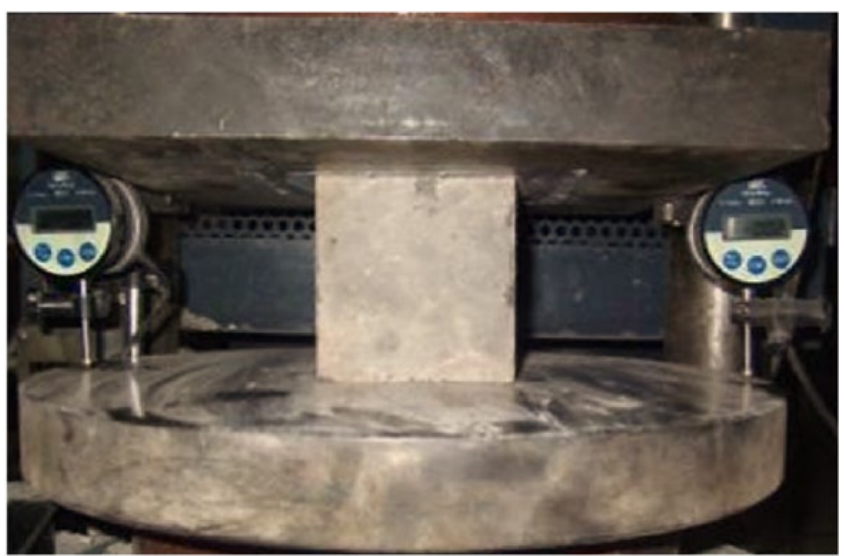

Figure I. Test set-up for compression tests.

Figure 2 shows the concrete uniaxial compressive stress-strain curves in the present tests, fibrereinforced UHPC differed from unreinforced composite in several ways. The composite stiffness increased after fibre addition, at the first cracking strength around $90 \mathrm{MPa}$, unreinforced composite fails abruptly while fibre-reinforced UHPC was seen a strain hardening and then a clear strainsoftening phase. The strain hardening and softening occurred due to the presence of fibres. The interaction between the fibres and the matrix contributed to ductile compressive failure where the concrete surface remained intact even at total strength loss.

It shall be noted that the present test set-up yielded an inaccurate strain measurement due to the platen restraint from the testing machine, and thus, the initial modulus was lower than the real value. Fibre material addition exerts profound influence on material tensile behaviour. Many researchers have attempted to develop test methods for the assessment of the tensile performance of fibre-reinforced concretes. Test methods have included both direct and indirect assessments, including some that have been standardized (Rilem, 2002). Direct testing method, that is, the uniaxial tensile testing (UTT), is widely used in academia; this method is considered to be complicated and requires advanced equipment and experimental skills. Splitting tensile test is generally carried out to obtain the tensile strength of concrete, and the stress field in the tests is actually a biaxial stress field with compressive stress three times greater than the tensile stress. In the case of fibre-reinforced concrete, previous studies have reported setting strain gages or LVDTs at the end surface of the specimen and obtaining the first cracking strength from the point at which displacement in the tensile direction increases remarkably. As a simple alternative to UTT, FPBT has been proposed (Stang and $\mathrm{Li}, 2004$ ) and widely adopted in the user community. It shall be noted that bending tests are not designed to determine the material tensile strain-hardening/strain-softening behaviour, but rather to constrain the material tensile properties such as the tensile strain capacity and/or tensile strength. When using the FPBT for identifying a stress-strain constitutive law, an inverse analysis is necessary to determine the uniaxial tensile behaviour (De Oliveira e Sousa and Gettu, 2006; Qian and Li, 2007; Walter and Olesen, 2005).

In the present study, FPBTs are conducted, the samples have a length of $400 \mathrm{~mm}$ with crosssection of $100 \times 100 \mathrm{~mm}$, and clear span and loading span are 300 and $100 \mathrm{~mm}$, respectively. Ultimate flexural strengths are calculated from the corresponding load using the formula for modulus of rupture given in ASTM C78 (2009), although the linear stress and strain distributions on which the formula is based no longer apply after the matrix has cracked. According to the test 


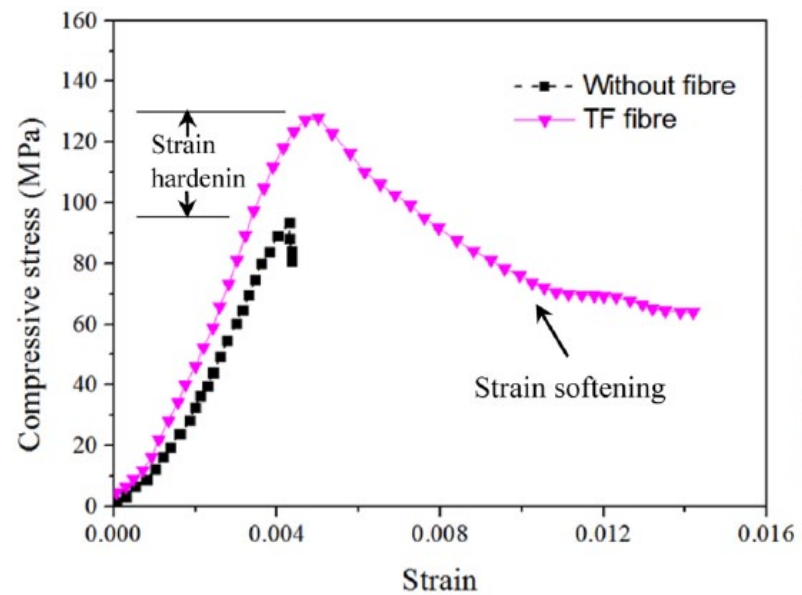

(a)

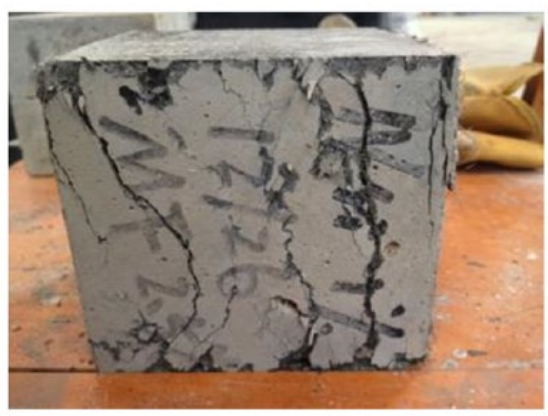

(b)

Figure 2. UHPC under uniaxial compression: (a) stress-strain curve and (b) specimen after test.

sample configuration, the flexural tensile strengths of UHPC with TF reinforcement can be derived as $25 \mathrm{MPa}$ (Figure 3).

To evaluate the uniaxial tensile strength and ultimate strain capacity for the present UHPC material, an inverse analysis on the FPBTs is carried out based on Japan Concrete Institute Standard JCI-S-003-2007 (Kanakubo, 2006). By adopting this method, it is assumed the stress distribution on the compression side is triangular, and the stress distribution on the tension side is uniform

$$
\begin{aligned}
& \varepsilon_{t u, b}=\phi_{u} \cdot D \cdot\left(1-x_{n l}\right) \\
& f_{t, b}=0.5 \cdot E \bullet \phi_{u} \cdot D \cdot x_{n l}^{2} /\left(1-x_{n l}\right)
\end{aligned}
$$

where $x_{n l}=-1+2 \cos (\theta / 3) ; \theta=\arccos \left(-1+6 m^{*}\right) ; m^{*}=M_{\max } /\left(E \cdot \phi_{u} \cdot B \cdot D^{3}\right) ; x_{n l}=x_{n} / D ; x_{n}$ is the distance from compressive edge to neutral axis (mm); $D$ is the depth of test specimen $(100 \mathrm{~mm}) ; M_{\max }$ is the maximum moment $\left(P_{\max } / 2 \times l / 3\right) ; \phi_{u}$ is the curvature at the maximum load and $B$ is the width of the specimen $(100 \mathrm{~mm})$.

The curvature measurement in the JCI method is based on two staggered (lower and upper) LVDTs on the specimen side. In the present study, curvature is expressed in relation with the midspan deflection as $\phi=216 \delta /\left(23 L^{2}\right)$ in which $\delta$ is the mid-span deflection and $L$ is the clear span between the supports.

After inputting all parameters into equations (1) and (2), the uniaxial tensile strength and ultimate strain for TF-reinforced UHPC are calculated and presented in Figure 4. The parameters shown in this figure are to be applied in the subsequent finite element (FE) analysis.

\section{Material dynamic performance}

As a relatively new material which varies in composition and fibre material mixture, dynamic material behaviour of UHPC is still under discussion. While some tests data showed that UHPC 


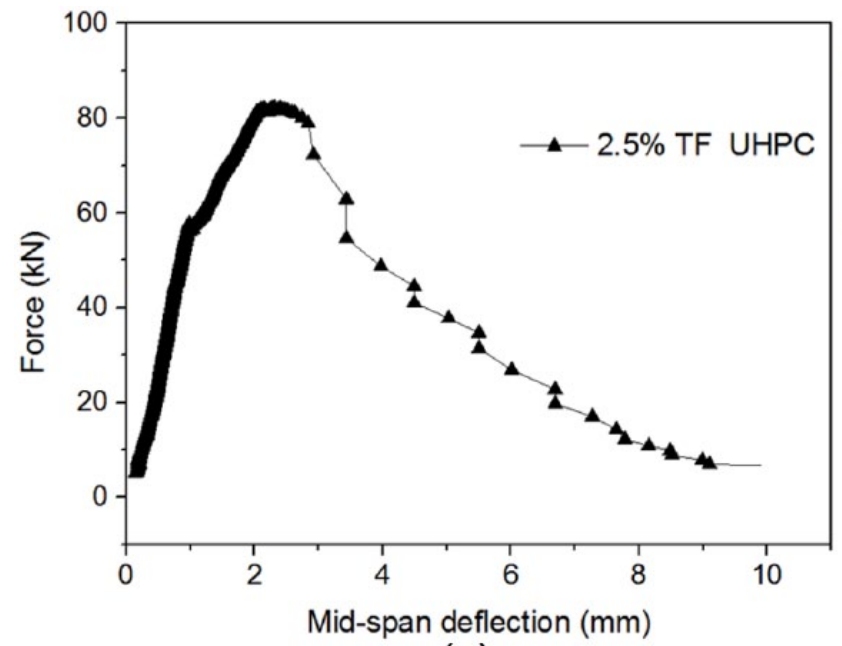

(a)

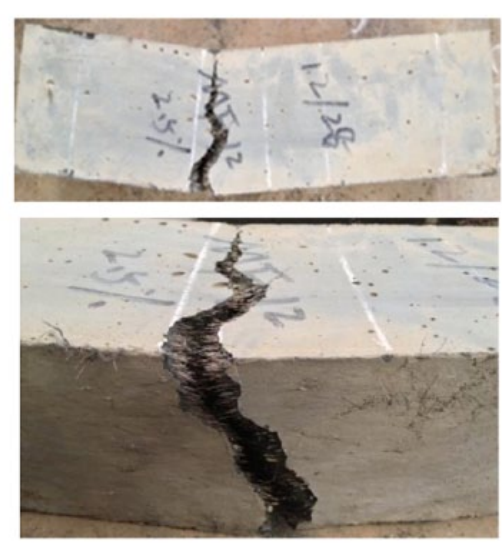

(b)

Figure 3. UHPC under FPBT: (a) force deflection curve and (b) specimen after test.

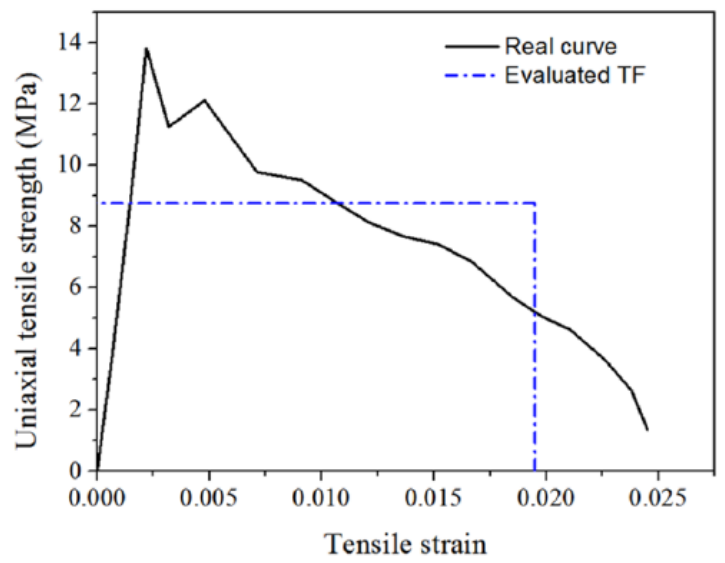

Figure 4. Inverse analysis on FPBTs.

exhibits similar increases in strength to NSC for strain rates in the range of 100-1000 s (Crawford $^{-1}$ et al., 2016). More test data reveal that UHPC is less rate sensitive than conventional concrete material. Chen et al. (2011) conducted dynamic tensile tests on steel fibre-reinforced concrete with various fibre volume fractions, and the largest dynamic increase factor (DIF) obtained was around 1.1 which is substantially smaller than NSC. Weidner (2013) conducted a series of drop hammer tests on both plain concrete and fibre-reinforced HSC, and it was observed that fibre-reinforced concrete specimens were less sensitive to the dynamic load as compared with NSC. Millard et al. (2010) performed dynamic flexural tensile test on ultra-HSC with different dosages of steel fibre. The results show that the strain rate enhancement of flexural strength for UHPC is reduced as the fibre percentage increases. It was explained that the fibres resist the lateral spreading of the cracks by bridging across regions of lower strength. Therefore, the beneficial effect of a restraint on lateral crack growth has already been partially accounted for by fibre reinforcement, resulting in higher 


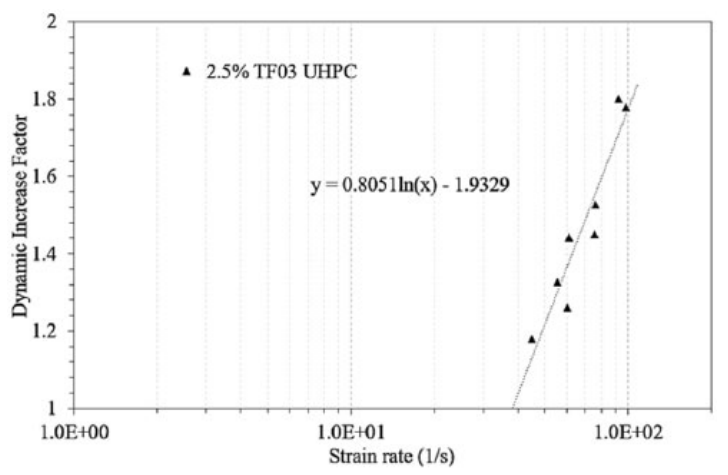

Figure 5. DIFs for UHPC under compression.

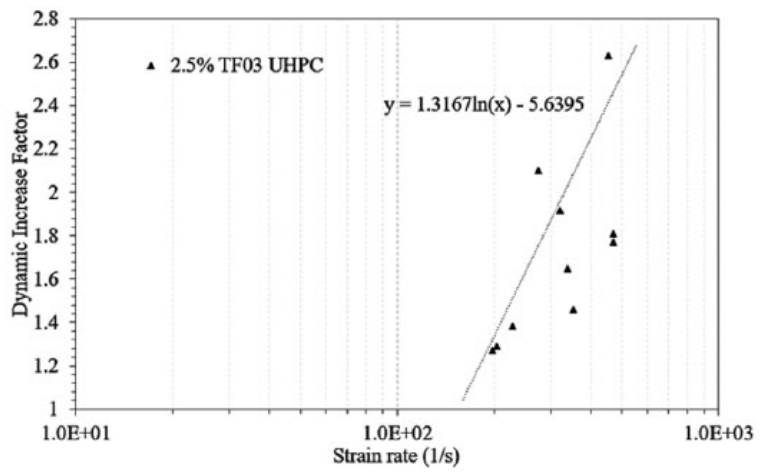

Figure 6. DIFs for UHPC under tension.

failure strength under quasi-static loading. Subsequently, the influence of the higher loading rate on reducing lateral crack development would be lessened.

In the present study, the DIFs for the UHPC under compression and tension are obtained through Split-Hopkinson-Pressure-Bar (SHPB) tests on cylinder samples and are shown in Figures 5 and 6, respectively (Su et al., 2016a, 2016b). In general, UHPC developed in this study is rate dependent but the rate sensitivity is lower than conventional concrete. In addition, for conventional concrete, according to the empirical formulae proposed by Malvar et al. (1998a, 1998b), a sharp increase in the slope of DIF curve happens at transition strain rate of 30 and $1 \mathrm{~s}^{-1}$ for compression and tension, respectively. Although without sufficient data, it can be predicted that such transition strain rate for UHPC material is higher than NSC. One possible explanation is that such transition stems from the increased lateral inertia effect, and in UHPC material, dispersed fibre material held together the concrete and reduced the lateral expansion which will postpone the sharp transition. In the subsequent study, the DIFs for TF-reinforced UHPC under compression and tension are considered in the numerical modelling of blast effects on UHPC elements.

\section{Numerical study on UHPC elements under and after blast loads}

Under blast loads, columns of UHPC containing steel fibres produced very high blast resistance by reducing the maximum displacement, enhancing the damage tolerance and eliminating secondary 
blast fragments. For the present UHPC material, field blast tests on columns with span length of $2.5 \mathrm{~m}$ and cross-section of $0.2 \mathrm{~m} \times 0.2 \mathrm{~m}$ were carried out in recent study. With a fixed stand-off distance of $1.5 \mathrm{~m}$, blast loads generated from $1 \mathrm{~kg}$ TNT equivalence to $35 \mathrm{~kg}$ TNT equivalence were designed in the tests; in addition, the effect of the axial load was also investigated. It is concluded that UHPC columns had high blast resistance and all of them showed flexural response and ductile failure while conventional HSC column showed brittle shear damage and concrete spallation. The detailed information including the test set-up, blast loads, column deflection time history can be found in previous publication (Xu et al., 2016).

In the present study, the numerical simulations on the UHPC columns under and after blast loads are carried out, and the analysis is performed in commercial hydro-code LS-DYNA. LS-DYNA provides a variety of concrete constitutive models including Mat_Pseudo_Tensor (MAT016), Mat_Geologic_Cap_Model (MAT025), Mat_Concrete_Damage (MAT072) (KCC model), Mat_Soil_Concrete (MAT078), Mat_Winfrith_Concrete (MAT084), Mat_Brittle_Damage (MAT096), Mat_Johnson_Holmquist_Concrete (MAT111), Mat_CSCM_Concrete (MAT159). Each of these models has its own merits and limitations. In previous studies concerning concrete structural modelling and testing, a number of plasticity-based (Malvar et al., 1997; Schwer and Murray, 1994) and tensor-based (Bažant et al., 2000; Cusatis et al., 2006) models have been developed and these concrete models typically have an unconfined compressive strength less than $40 \mathrm{MPa}$. Due to its unique properties, there is no constitutive model that is suitable in first-principle FE analysis for UHPC. In some pioneering numerical work, Mat_Concrete_Damage (MAT072) (KCC model) was adopted to simulate the UHPC under static (Magallanes et al., 2010) and dynamic loads (Zhang et al., 2016), and the model features automatic parameter generation that is achieved by inputting concrete unconfined compression strength. KCC model also allows userdefined material strain rate curve for dynamic analysis. However, it shall be noted that KCC model was developed based on NSC with uniaxial compressive strength of $45.4 \mathrm{MPa}$, whereas the strength and post-yielding behaviours of UHPC are significantly different. Therefore, the parameters generated by KCC concrete model shall be modified/updated based on available UHPC tests before they can be applied to model the behaviours of UHPC elements.

Based on the available tests data, the modification on the KCC default parameters is presented. The modified parameters involve $f_{t}$, which is the uniaxial tensile strength; $b_{1}$, which governs the compressive damage and softening behaviour; $w l z$, which governs the fracture energy of each element. Single element tests in accordance with mesh size used in the structural analysis was first simulated with the default parameters. The area under the post-peak portion of the stress-strain curves are then computed and compared to the experimental stress-strain curve. The calibration involves several iterations to equalize the area and the resultant was utilized as the input for the relevant material data. Without losing generality, the TF fibre-reinforced UHPC and their components are discussed in the following study.

\section{Single element test}

The basic performances of the UHPC element built by KCC model are examined through single element simulations subjected to stress paths similar to that done in the material static tests. It is worth noting that the single element size shall be consistent with the subsequent structural analysis as element size is influential on the damage features of the KCC model.

Single element under unconfined uniaxial tensile tests was first performed and the results are shown in Figure 7. Since the uniaxial tension test data were not available, the model was calibrated with the analytical results from the inverse analysis on the FPBTs, as shown in Figure 4. A value of $b_{2}$ is first chosen and boundary motion is prescribed on the single element to simulate uniaxial 


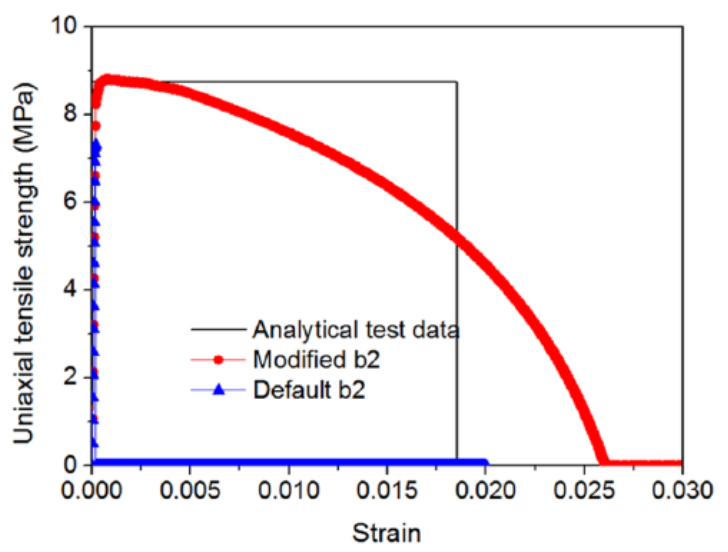

Figure 7. Single model under UUT test.

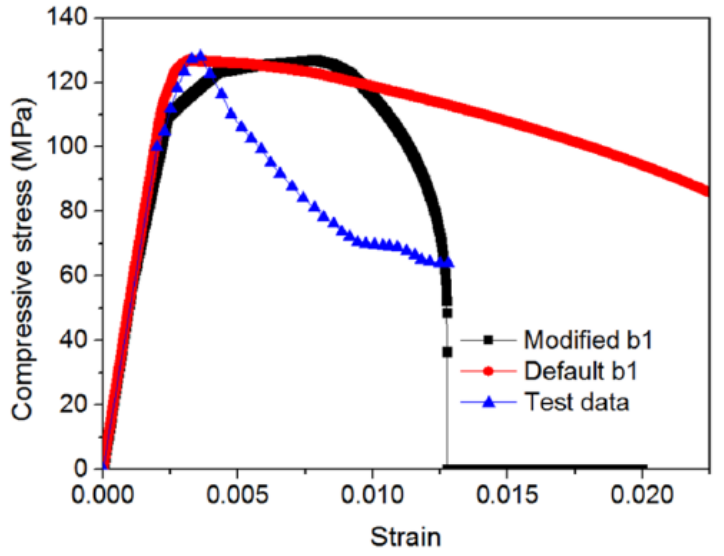

Figure 8. Single model under UCC test.

tension loading. This process is repeated by changing the value of $b_{2}$ and re-running the analysis until $G f / h$ coincides with the area under the FE stress-strain curve, where $G f$ is the strain energy and $h$ is the single element length. After updating the parameter $b_{2}$ from 1.35 to -5.5 , a better curve fitting result on the material uniaxial tensile performance is obtained as shown in Figure 7.

The stress-strain curves for single element unconfined uniaxial compression tests are shown in Figure 8. It is noted that $\mathrm{KCC}$ model with default parameters showed excessive post-yielding behaviour. After updating the $b_{1}$ from 1.6 to 1.0, material softening behaviour was better modelled despite some discrepancy was observed.

The parameters before and after update are shown in Table 2.

\section{Model validation by field blast tests}

Under high strain rate loading condition, the DIFs for both UHPC and steel tendon shall be considered in the material model. For UHPC materials, the tests data shown in Figures 5 and 6 are adopted. For stirrup steel tendon with $300 \mathrm{MPa}$ yielding strength in the field tests (Xu et al., 
Table 2. Material parameters used in KCC model.

\begin{tabular}{lll}
\hline Model parameter & Default value & Updated value \\
\hline$f_{c}$ & $127 \mathrm{MPa}$ & No update \\
$f_{t}$ & $7.6 \mathrm{MPa}$ & $8.8 \mathrm{MPa}$ \\
$B_{1}$ & 1.6 & 1.0 \\
$B_{2}$ & 1.35 & -5.5 \\
$w l z$ & $25.4 \mathrm{~mm}$ & $6.00 \mathrm{~mm}$ \\
\hline
\end{tabular}

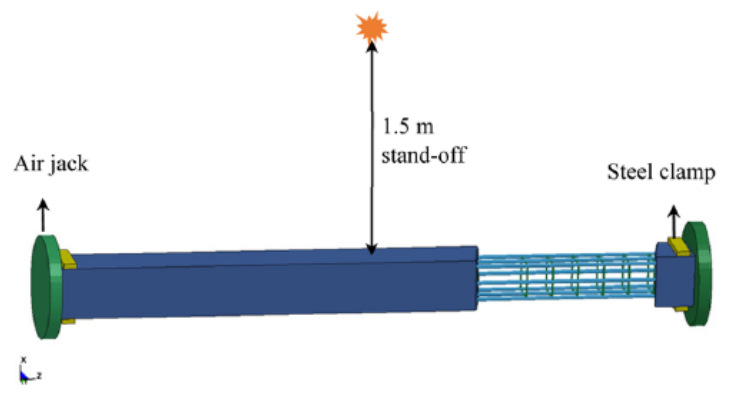

Figure 9. FE mode of UHPC column under blast loads.

2016), the formulae proposed by Malvar (1998) are used for generating the DIFs versus different strain rates. It is worth noting that Malvar's formulae are applicable for steel with yield strengths varying from 42 to $103 \mathrm{ksi}(290-710 \mathrm{MPa})$; therefore, they cannot be used for the longitudinal tendon with $1400 \mathrm{MPa}$ yielding strength in the present tests. To authors' best knowledge, there is no reliable DIF data for the high strength steel tendon in the open literature, considering the rate dependence of steel reduces with the increase of the steel yielding strength, no dynamic increase factor is considered for the high strength longitudinal tendon, and this assumption is deemed reasonable and conservative.

The numerical set-up for the UHPC under field blast test is shown in Figure 9, the column is constrained by the rigid steel clamps at both ends, and two circular steel plates with a diameter of $400 \mathrm{~mm}$ were placed at the column ends to simulate the air jack. Solid elements of $10 \mathrm{~mm}$ cube with a single integration point were used to model the concrete, and $10 \mathrm{~mm}$ beam elements were used for the reinforcement bars and the stirrups. Numerical convergence study showed that further decrease of the mesh size has limited effect on the numerical results but leads to an excessive calculation time. Therefore, a mesh size of $10 \mathrm{~mm}$ is used in the study. It is worth noting that the same element size shall be used in the single element calibration for damage characteristics of UHPC.

The axial load is applied using the LOAD_NODE_SET function. The air blast load is simulated by the empirical LOAD_BLAST. It is worth noting that such implementation is based on empirical blast load models described in TM5-855-1 US army handbook, and it is limited to the treatment of hemispherical TNT charges on the ground or spherical TNT charges in the air. However, in real cases, the explosives used are not always in these shapes, and it was found that the detonation point within the explosive and the ratio of length to diameter in cylinder explosives can significantly influence the blast effects. In the present study, both the longitudinal and stirrup tendon are simulated by MAT_PIECEWISE_LINEAR_PLASTICITY (MAT24). This model allows the definition of arbitrary stress versus strain curve and arbitrary strain rate curve. Also, steel failure based on a plastic strain of 0.15 is defined. 


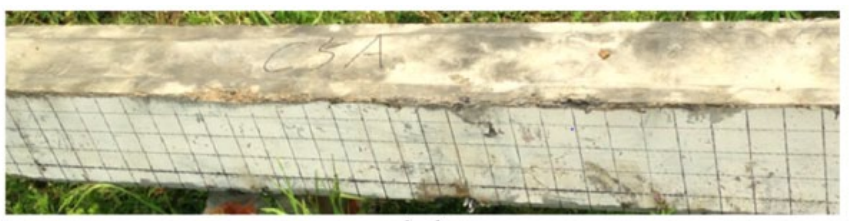

(a)

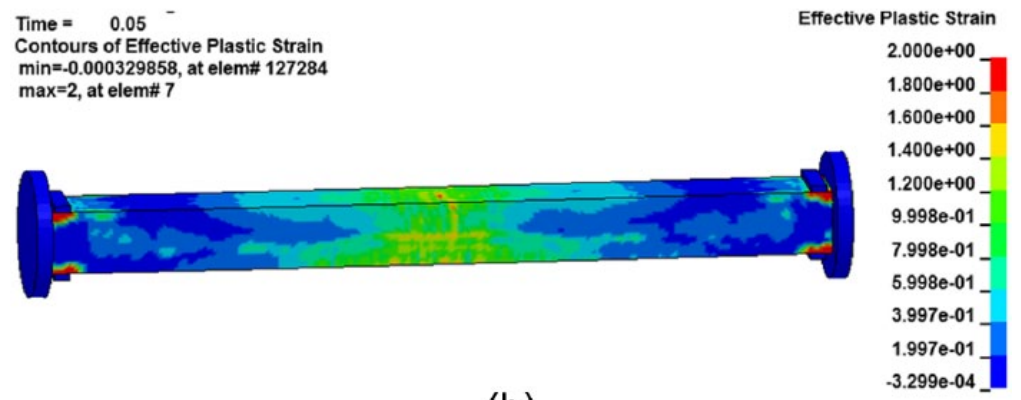

(b)

Figure 10. Column damage after $10 \mathrm{~kg}$ TNT equivalence detonation at $1.5 \mathrm{~m}$ stand-off (a) post-damage UHPC column; (b) column damage in numerical simulation.

The first model calibration is performed on UHPC column under $10 \mathrm{~kg}$ TNT equivalence detonation in which no damage was observed in the field test (see Figure 10(a)). Figure 10(b) shows the column after $50 \mathrm{~ms}$ from detonation, and the effective plastic strain contour shown in the plot represents the damage level in the UHPC material. The column suffers minimal damage around the mid-span while primary damage occurs at the column boundary due to the contact with the steel clamp and axial loading plate.

Mid-span deflection time history is compared with the field measurement as shown in Figure 11. It is noted that the numerical model underestimates the peak mid-span deflection despite the residual deflection is captured with good accuracy (around $2 \mathrm{~mm}$ ), and the predicted vibration frequency is higher than the field test measurement. There are two reasons accounting for these inaccurate predictions. First, the material model for the UHPC is not complete, despite some calibrations are carried out based on the available uniaxial compression and flexural test data, the behaviour of UHPC under direct tensile and confinement (triaxial tests) is not well established. In addition, the shear dilatancy is not understood in UHPC material, it is known that geomaterials including concrete subjected to deviatoric loading exhibit dilatancy, and this behaviour is engendered by local failures due to distributed microcracking and formation of shear bands. However, in most UHPC material including the present formation, coarse aggregates are omitted and fibres are included throughout cementitious matrix which leads to difficulty in understanding the material dilatancy behaviour. The other reason for the inaccurate peak deflection prediction and vibration frequency prediction is the boundary set-up. In the field blast tests, the clamps are hand-fixed by the steel bolts. Under severe blast loading, the bolts fixture became loose, leading to a boundary set-up more close to simply support, and this explains why the first negative peak from the numerical model is clearly smaller than the field record. Due to the incomplete knowledge in the UHPC material and difficulty in FE model to precisely reproduce the column boundary set-up, the present model is deemed acceptable in predicting UHPC columns under blast loads.

The other model calibration is performed on UHPC column under $35 \mathrm{~kg}$ TNT equivalence detonation in which combined damage including major flexure and minor shear was observed in the 


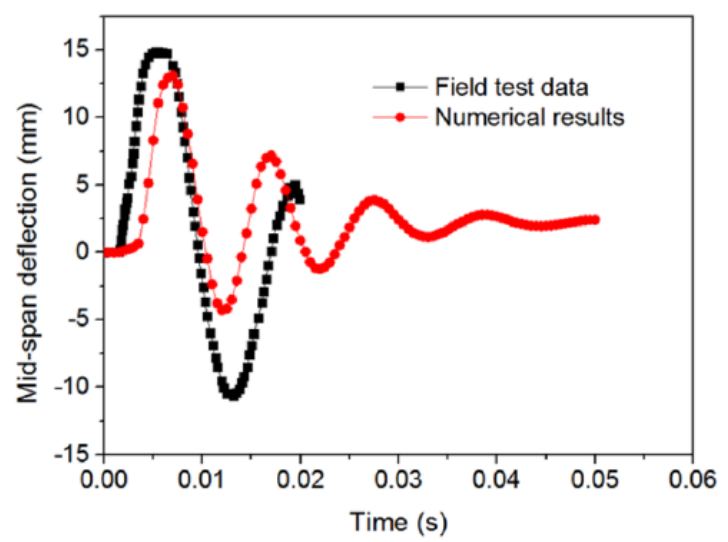

Figure I I. Mid-span deflection under $10 \mathrm{~kg}$ TNT detonation.

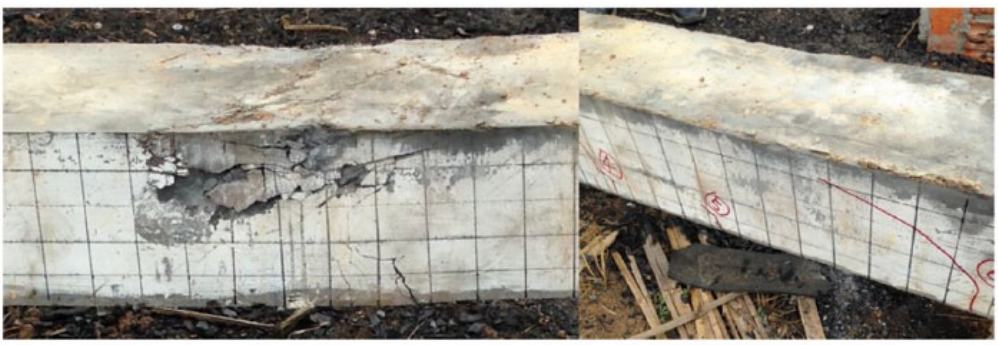

(a)

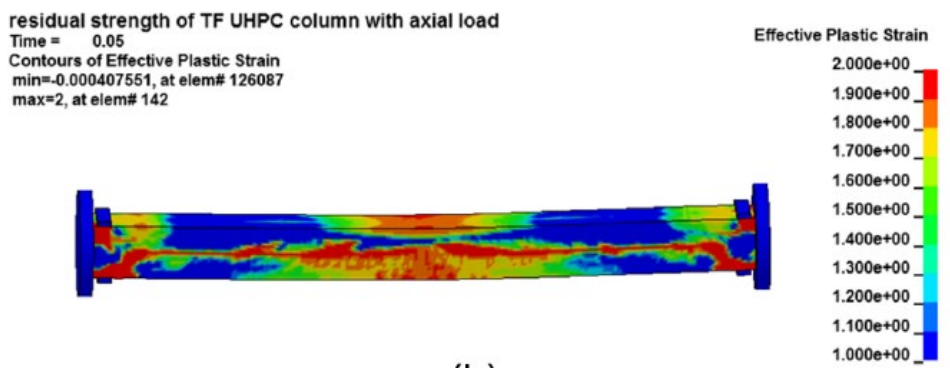

(b)

Figure 12. Column damage after $35 \mathrm{~kg}$ TNT equivalence detonation at $1.5 \mathrm{~m}$ stand-off: (a) field damage observation and (b) numerical damage prediction.

field test (see Figure 12(a)). It is observed that numerical model yields reasonable damage prediction on the UHPC column.

Due to the excessive blast loads from $35 \mathrm{~kg}$ TNT detonation at $1.5 \mathrm{~m}$ stand-off distance, the LVDT at mid-span was knocked off in the test, and only the LVDT that located $490 \mathrm{~mm}$ away from the boundary survived after the detonation. Comparison on the column deflection at that location is shown in Figure 13, it is noted that numerical results yielded reasonable accurate peak and residual deflection, and the discrepancies are deemed to be engendered by the same reasons explained in last case study. 


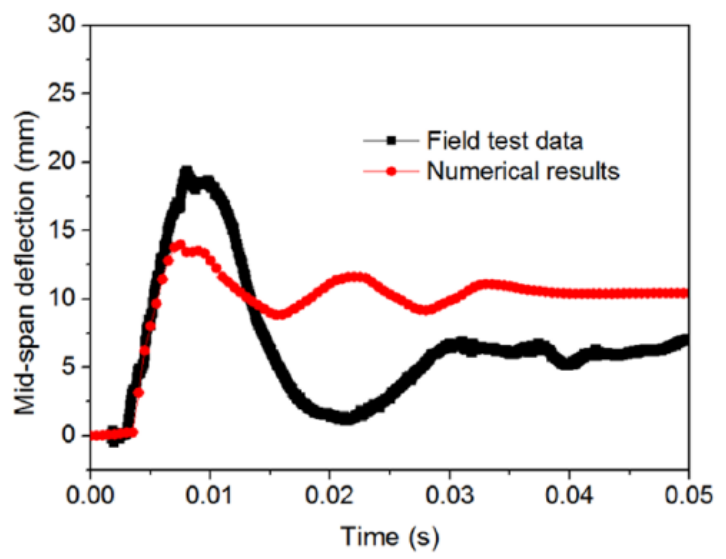

Figure 13. Column deflection under $35 \mathrm{~kg}$ TNT detonation.

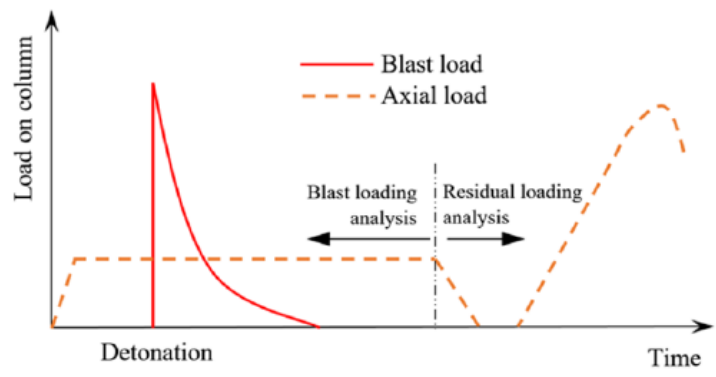

Figure 14. Schematic loading on UHPC column.

\section{Residual load-carrying capacity of UHPC column}

To quantitatively study the structural damage after blast loads, damage criterion based on SingleDegree-of-Freedom (SDOF) models and component deflections were widely adopted (Mays and Smith, 1995). However, these criteria may not be accurate when describing structural damage under close-in blast loads in which structural component could suffer combined damage including concrete spallation, shear and excessive flexure. To better describe the structural damage, a performance-based damage evaluation method was proposed by Shi et al. (2008) in which column residual loading capacity was picked as the damage index.

The damage index $D$ for post-blast UHPC columns is defined as (Shi et al., 2008)

$$
D=\left(1-P_{\text {residual }} / P_{\max }\right) \times 100 \%
$$

where $P_{\max }$ is the maximum load-carrying capacity and $P_{\text {residual }}$ is the post-blast load-carrying capacity of the column.

Following this damage evaluation method, residual load-carrying capacity of the post-blast column is simulated using the present numerical model. The loading scheme in the numerical analysis is shown schematically in Figure 14. 


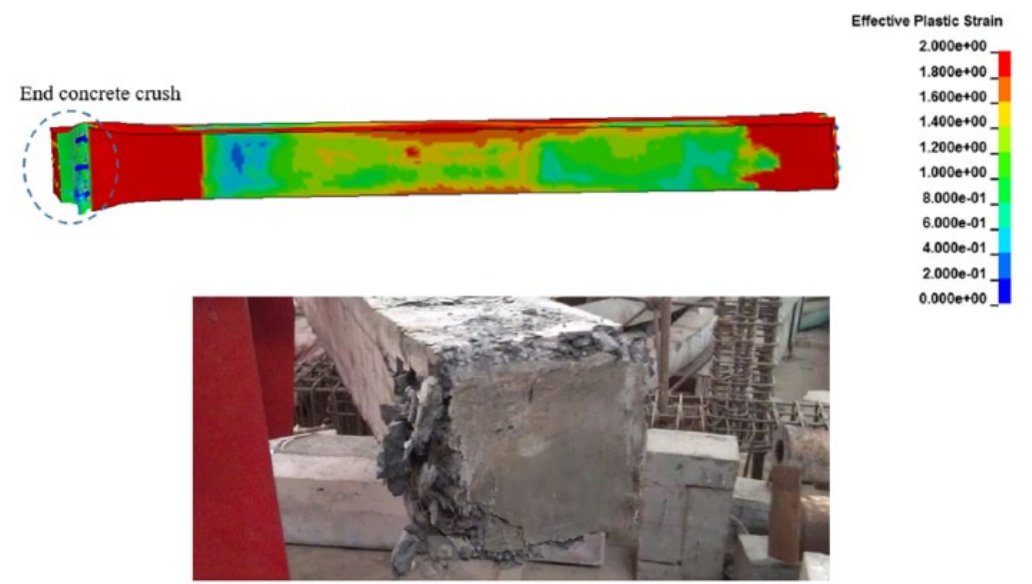

(a)

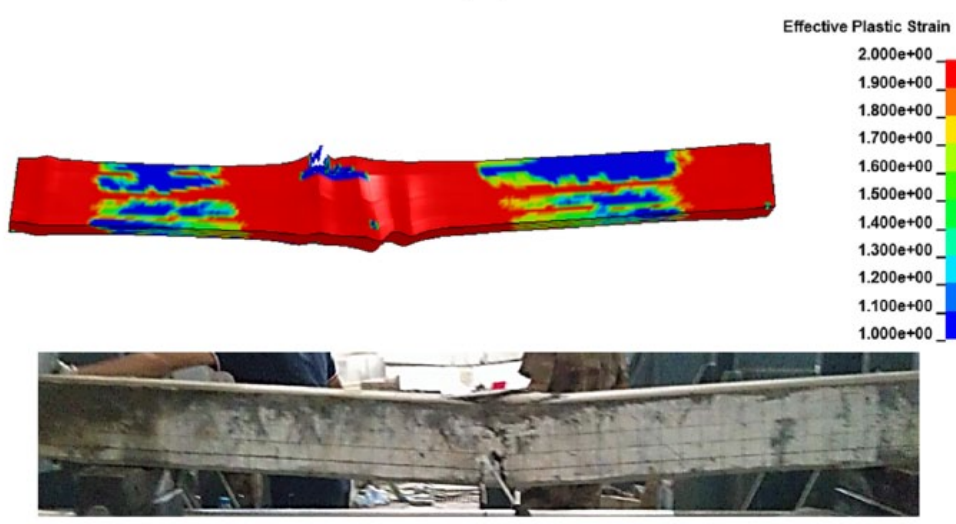

(b)

Figure 15. Column damage in residual loading tests: (a) column that experienced $10 \mathrm{~kg}$ TNT equivalence explosion and (b) column that experienced $35 \mathrm{~kg}$ TNT equivalence explosion.

UHPC columns in the post-blast axial loading tests are shown in Figure 15, the column that experienced $10 \mathrm{~kg}$ TNT equivalence in the field remains straight and intact until sudden failure occurs on the boundary elements, and the load-carrying capacity is $95 \%$ of the precinct column. For the column underwent $35 \mathrm{~kg}$ TNT equivalence in the field tests, damage initiates at mid-span where flexure damage was observed in the blast test, and the column preserved $76 \%$ of its original load-carrying capacity. Both the numerical results agree well with the test results reported in $\mathrm{Li}$ et al. (2017).

\section{P-I diagram for the UHPC column}

For a given blast loading scenario, P-I diagrams are commonly used for quick evaluation of the structural damage. A P-I diagram is composed of a series of iso-damage curves defining different damage levels. In the present study, column damage based on residual loading capacity is adopted and three damage levels, that is, $20 \%, 40 \%$ and $60 \%$, are considered. It should be mentioned that 


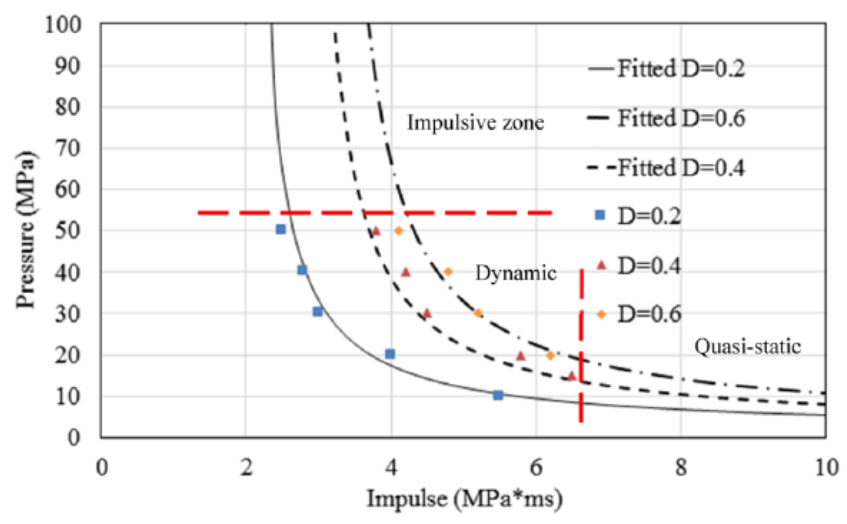

Figure 16. P-I diagram for the present UHPC column.

Table 3. Value of the parameters $\alpha$ and $\beta$.

\begin{tabular}{lllll}
\hline$D$ & $P_{0}(\mathrm{MPa})$ & $I_{0}$ (MPams) & $\alpha$ & $\beta$ \\
\hline 0.2 & 1.5 & 2 & 5.3 & 1.3 \\
0.4 & 1.8 & 2.75 & 5.5 & 1.4 \\
0.6 & 2.4 & 3.1 & 5.5 & 1.35 \\
\hline
\end{tabular}

since it is difficult to obtain the exact critical damage for damage boundaries, the numerical data obtained in a range are used for the curve fitting. For example, all the data around $D=40 \%$ are used to get the curve for $D=40 \%$. The range of the data around the aimed damage degree is decided by trial and error, so that the derived P-I curves are the approximate upper bounds of the simulated data for the respective damage levels.

After examination of the fitted P-I curves, it is found that they can be expressed analytically as

$$
\left(P-P_{0}\right) \times\left(I-I_{0}\right)=\alpha\left(P_{0}+I_{0}\right)^{\beta}
$$

where $P_{0}$ is the pressure asymptote for individual damage level, and $I_{0}$ is the impulsive asymptote for individual damage level. $\alpha$ and $\beta$ are constants, which are related to the column configuration and degree of damage.

For the UHPC columns tested in the field tests, the P-I diagrams are shown in Figure 16, and the parameter $\alpha$ and $\beta$ are shown in Table 3. It is worth noting that it is extremely difficult to obtain the accurate damage level on the column, and therefore, pressure and impulse combinations that yield damage around the pre-determined damage level are taken into the curve fitting process.

Three distinctive zones can be characterized in the P-I diagram, that is, the impulsive zone, dynamic zone and quasi-static zone. P-I combination that lies in each of these zones induces different damages on the same column. In impulsive zone, column tends to fail under shear, and in the quasi-static zone, column is prone to flexural failure, and in the dynamic zone, a combined shear and flexure failure is commonly seen. These damage modes are shown in Figure 17.

It is noted that damage constants $\alpha$ and $\beta$ are almost independent of the damage level, and therefore, averaged values of $\alpha$ and $\beta$ from $D=0.4$ are tested for the other two damage levels, and comparison is shown in Figure 18 in which very minor difference is noted. 


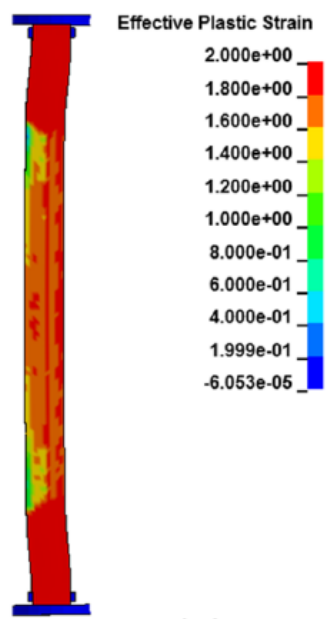

(a)

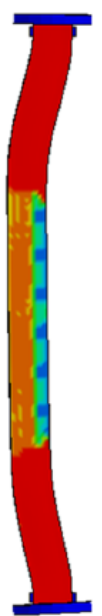

(b)

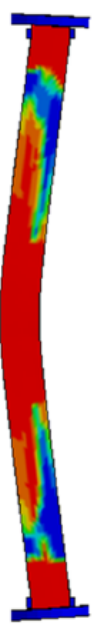

Effective Plastic Strain $2.000 \mathrm{e}+00$ $1.800 \mathrm{e}+00$ $1.600 \mathrm{e}+00$ $1.400 \mathrm{e}+00$ $1.199 \mathrm{e}+00$ 9.992e-01 7.991e-01 $5.989 \mathrm{e}-01$ $3.988 \mathrm{e}-01$ $1.986 \mathrm{e}-01$ $-1.517 \mathrm{e}-03$

(c)

Figure I7. Damage modes of UHPC column: (a) impulsive load, (b) dynamic load and (c) quasi-static load.

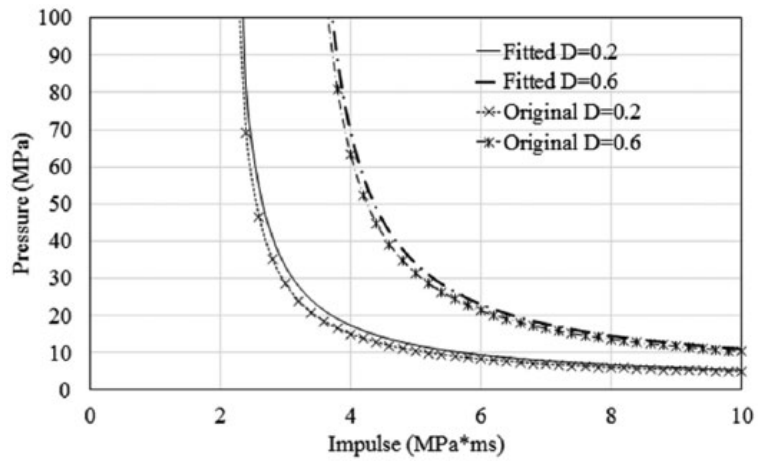

Figure I 8. P-I diagram with different damage constants.

\section{Parametric studies on post-blast loading capacity of UHPC columns}

Based on the above numerical model, parametric studies on UHPC columns considering different concrete strength, column size and reinforcement configuration are carried out. P-I diagrams representing three structural damage levels, that is, $20 \%, 40 \%$ and $60 \%$, are presented. In all columns, the pre-blast axial load application is assumed to be $20 \%$ of undamaged column loading capacity. Table 4 summarizes the parameters investigated in the present study.

\section{Column cross-section size}

In order to investigate the effect of column size on the UHPC column P-I diagram, the P-I diagrams of three UHPC columns with different column cross-section size, that is, 200, 250 and $300 \mathrm{~mm}$, are derived using the proposed method. 
Table 4. Range of the parameters studied.

\begin{tabular}{llll}
\hline Cross-section side length $(\mathrm{mm})$ & Height $H(\mathrm{~mm})$ & Concrete strength $f c^{\prime}(\mathrm{MPa})$ & Reinforcement (ratio $\rho$ ) \\
\hline 200 & 2500 & 127 & 0.040 \\
250 & 3000 & 140 & 0.023 \\
300 & 3500 & 160 & 0.010
\end{tabular}

Table 5. Effect of column cross-section size on pressure and impulsive asymptotes.

\begin{tabular}{|c|c|c|c|c|c|c|}
\hline \multirow{2}{*}{$\begin{array}{l}\text { Cross-section } \\
\text { side length }(\mathrm{mm})\end{array}$} & \multicolumn{2}{|l|}{$D=0.2$} & \multicolumn{2}{|l|}{$D=0.4$} & \multicolumn{2}{|l|}{$D=0.6$} \\
\hline & $P_{0}(\mathrm{MPa})$ & $I_{0}$ (MPa ms) & $P_{0}(\mathrm{MPa})$ & $I_{0}$ (MPams) & $P_{0}(\mathrm{MPa})$ & $I_{0}$ (MPams) \\
\hline 200 & 1.5 & 2 & 1.8 & 2.75 & 2.4 & 3.1 \\
\hline 250 & 2.3 & 2.6 & 3 & 3.35 & 3.2 & 5 \\
\hline 300 & 3 & 3 & 3.7 & 3.5 & 3.9 & 5.5 \\
\hline
\end{tabular}

Table 6. Effect of concrete strength on pressure and impulsive asymptotes.

\begin{tabular}{|c|c|c|c|c|c|c|}
\hline \multirow{2}{*}{$\begin{array}{l}\text { Concrete } \\
\text { strength (MPa) }\end{array}$} & \multicolumn{2}{|l|}{$D=0.2$} & \multicolumn{2}{|l|}{$D=0.4$} & \multicolumn{2}{|l|}{$D=0.6$} \\
\hline & $P_{0}(\mathrm{MPa})$ & $I_{0}$ (MPa ms) & $P_{0}(\mathrm{MPa})$ & $I_{0}$ (MPa ms) & $P_{0}(\mathrm{MPa})$ & $I_{0}$ (MPa ms) \\
\hline 127 & 1.5 & 2 & 1.8 & 2.75 & 2.4 & 3.1 \\
\hline 140 & 1.7 & 2.2 & 2.1 & 2.95 & 2.45 & 3.3 \\
\hline 160 & 2 & 2.5 & 2.4 & 3.15 & 2.7 & 3.45 \\
\hline
\end{tabular}

Table 5 shows the pressure asymptotes and impulsive asymptotes of the P-I curves, from which one can see that increasing the column size results in an increment on both the pressure and impulse asymptotes of the P-I curve. This is because increasing the column size will increase the mass, shear strength and the bending strength of the column. Despite the blast loads acting on the column will also increase due to the increase in the loading surface, the increment of the blast resistance overweights the increment in the external loading.

\section{Concrete strength}

Columns with concrete strength of 127,140 and $160 \mathrm{MPa}$ are analysed to generate the corresponding P-I diagrams. The pressure asymptotes and impulsive asymptotes of the P-I curves are given in Table 6. It shows that increasing the concrete strength will increase both the pressure and the impulsive asymptotes of the P-I curve. This can be explained by the fact that the concrete strength contributes to both the shear and bending strength of the column.

\section{Longitudinal reinforcement ratio, $\rho$}

The comparisons of the pressure asymptotes and impulsive asymptotes of P-I curves for UHPC columns with different longitudinal reinforcement ratios are given in Table 7. It indicates that with the increase of the longitudinal reinforcement ratio, the pressure asymptote of the P-I curve will increase, which is expected. It is also noted that the impulsive asymptote is less influenced by the 
Table 7. Effect of reinforcement ratio on pressure and impulsive asymptotes.

\begin{tabular}{|c|c|c|c|c|c|c|}
\hline \multirow{2}{*}{$\begin{array}{l}\text { Reinforcement } \\
\text { ratio }\end{array}$} & \multicolumn{2}{|l|}{$D=0.2$} & \multicolumn{2}{|l|}{$D=0.4$} & \multicolumn{2}{|l|}{$D=0.6$} \\
\hline & $P_{0}(\mathrm{MPa})$ & $I_{0}$ (MPa ms) & $P_{0}(\mathrm{MPa})$ & $I_{0}$ (MPa ms) & $P_{0}(\mathrm{MPa})$ & $I_{0}$ (MPams) \\
\hline 0.040 & 1.5 & 2 & 1.8 & 2.75 & 2.4 & 3.1 \\
\hline 0.023 & 1.2 & 2.1 & 1.5 & 2.8 & 2.1 & 2.9 \\
\hline 0.010 & 1.0 & 2 & 1.3 & 2.65 & 2 & 3 \\
\hline
\end{tabular}

Table 8. Effect of column height on pressure and impulsive asymptotes.

\begin{tabular}{|c|c|c|c|c|c|c|}
\hline \multirow{2}{*}{$\begin{array}{l}\text { Column height } \\
(\mathrm{mm})\end{array}$} & \multicolumn{2}{|l|}{$D=0.2$} & \multicolumn{2}{|l|}{$D=0.4$} & \multicolumn{2}{|l|}{$D=0.6$} \\
\hline & $P_{0}(\mathrm{MPa})$ & $I_{0}$ (MPa ms) & $P_{0}(\mathrm{MPa})$ & $I_{0}$ (MPa ms) & $P_{0}(\mathrm{MPa})$ & $I_{0}$ (MPa ms) \\
\hline 2500 & 1.5 & 2 & 1.8 & 2.75 & 2.4 & 3.1 \\
\hline 3000 & 0.9 & 1.4 & 1.05 & 2.25 & 1.2 & 2.9 \\
\hline 3500 & 0.7 & 1.0 & 0.95 & 2.05 & 1 & 2.6 \\
\hline
\end{tabular}

reinforcement ratio. This is because increasing the longitudinal reinforcement ratio can significantly increase the bending strength of the UHPC column, but has little contribution to the shear strength.

\section{Column height, $H$}

The P-I diagrams for another three columns with different column heights are derived to examine the column height effect. Table 8 shows the pressure asymptotes and impulsive asymptotes of the P-I curves, from which one can see that both the pressure asymptote and impulsive asymptote decrease with the column height. This result is consistent with the fact that when the column is higher, the blast load on its surface increases and column is more prone to damage, especially when the blast load is quasi-static. However, it should be noted that this result is obtained based on the assumption of uniformly distributed blast loads on the column. If blast load is very close to column base or surface, concrete spall will be dominating the structural damage (Li and Hao, 2014).

\section{Analytical formulae to generate P-I diagram}

\section{Derivations of the analytical formulae}

Based on the numerical results, analytical formulae are developed to predict the pressure asymptotes and impulsive asymptotes for the P-I curves when the degree of damage equals $0.2,0.4$ and 0.6 , which are the critical value between different damage levels defined in this study.

Using the least-squares fitting method, the pressure asymptote $P_{0}(D)$ and impulsive asymptote $I_{0}(D)$ are derived from numerical simulation data as a function of longitudinal reinforcement ratio $\rho$, concrete strength $f c^{\prime}$, column height $H$ and column cross-section size $W$. They are

$$
\begin{aligned}
& P_{0}(0.2)=-0.864 H / 1000+0.0157 f c^{\prime}+15.4 \mathrm{~W} / 1000+16.39 \rho-2.1 \\
& I_{0}(0.2)=-1.05 H / 1000+0.0149 f c^{\prime}+10.3 \mathrm{~W} / 1000-1.15 \rho+0.716
\end{aligned}
$$




$$
\begin{aligned}
& P_{0}(0.4)=-0.979 \mathrm{H} / 1000+0.0189 f c^{\prime}+20.0 \mathrm{~W} / 1000+16.89 \rho-2.82 \\
& I_{0}(0.4)=-0.782 \mathrm{H} / 1000+0.0119 f c^{\prime}+8.18 \mathrm{~W} / 1000+2.52 \rho+1.47 \\
& P_{0}(0.6)=\exp \left(-1.06 \mathrm{H} / 1000+0.00345 f c^{\prime}+5.01 \mathrm{~W} / 1000+6.44 \rho+1.84\right) \\
& I_{0}(0.6)=-0.551 \mathrm{H} / 1000+0.0091 f c^{\prime}+26.1 \mathrm{~W} / 1000+7.71 \rho-2.15
\end{aligned}
$$

\section{Conclusion}

In this article, a numerical study to analyse the UHPC column damage under blast loads is conducted. The material model is calibrated with the available material tests data, and the structural model is calibrated with the field test data. The results show that KCC model, which is popular in use for prediction concrete damage under blast loads, shall be carefully modified before applying on UHPFRC. It is also worth pointing out that more extensive experimental studies on the material uniaxial and triaxial behaviour shall be studied to complete the material model in numerical analysis.

Performance-based criteria for UHPC columns are defined based on the residual axial loadcarrying capacity. The P-I diagrams for UHPC column tested in the field blast experiments are derived from the numerical simulations. Following the numerical analysis, analytical equations for the P-I diagrams for this particular column are proposed.

Parametric studies are carried out to study the effect of column height, cross-section size, concrete strength and reinforcement ratio on the P-I diagram of the UHPC column. Based on the numerical results, analytical formulae to predict the pressure asymptotes and impulsive asymptotes for the P-I curves are derived.

\section{Declaration of Conflicting Interests}

The author(s) declared no potential conflicts of interest with respect to the research, authorship and/or publication of this article.

\section{Funding}

The author(s) disclosed receipt of the following financial support for the research, authorship, and/or publication of this article: The authors gratefully acknowledge the financial support of the Australian Research Council grant DP160104661 and the National Basic Research Programme 2015 CB058002.

\section{References}

Aoude H, Dagenais FP, Burrell RP, et al. (2015) Behavior of ultra-high performance fiber reinforced concrete columns under blast loading. International Journal of Impact Engineering 80: 185-202.

ASTM C78-09:2009 (2009) Standard test method for flexural strength of concrete (using simple beam with third-point loading).

Bažant ZP, Caner FC, Carol I, et al. (2000) Microplane model M4 for concrete. I: formulation with workconjugate deviatoric stress. Journal of Engineering Mechanics 126(9): 944-953.

Chen R, Liu Y, Guo X, et al. (2011) Dynamic tensile properties of steel fiber reinforced concrete. In: Proulx T (ed.) Dynamic Behavior of Materials, vol. 1. New York: Springer, pp. 37-42.

Crawford JE, Magallanes JM, Whittaker A, et al. (2016) Modeling of pristine and damaged UHPFRC materials for use in performing blast and projectile penetration analyses. In: Proceedings of the 4th international conference on protective structures, Beijing, China, 18-21 October. 
Cusatis G, Bažant ZP and Cedolin L (2006) Confinement-shear lattice CSL model for fracture propagation in concrete. Computer Methods in Applied Mechanics and Engineering 195(52): 7154-7171.

De Oliveira e Sousa JLA and Gettu R (2006) Determining the tensile stress-crack opening curve of concrete by inverse analysis. Journal of Engineering Mechanics 132(2): 141-148.

Ellis B, DiPaolob BP, McDowell DL, et al. (2014) Experimental investigation and multiscale modeling of ultra-high-performance concrete panels subject to blast loading. International Journal of Impact Engineering 69: 95-103.

Hassan AMT, Jones SW and Mahmud GH (2012) Experimental test methods to determine the uniaxial tensile and compressive behaviour of ultra high performance fibre reinforced concrete (UHPFRC). Construction and Building Materials 37: 874-882.

Kanakubo T (2006) Tensile characteristics evaluation method for ductile fiber-reinforced cementitious composites. Journal of Advanced Concrete Technology 4(1): 3-17.

Li J and Hao H (2014) Numerical study of concrete spall damage to blast loads. International Journal of Impact Engineering 68: 41-55.

Li J, Wu C and Hao H (2015) Investigation of ultra-high performance concrete slab and normal strength concrete slab under contact explosion. Engineering Structures 102: 395-408.

Li J, Wu C, Hao H, et al. (2016) Experimental investigation of ultra-high performance concrete slabs under contact explosions. International Journal of Impact Engineering 93: 62-75.

Li J, Wu C, Hao H, et al. (2017) Post-blast capacity of ultra-high performance concrete columns. Engineering Structures 134: 289-302.

Magallanes J, Wu Y, Morrill KB, et al. (2010) Feasibility studies of a plasticity-based constitutive model for ultra high performance fiber-reinforced concrete. Available at: http://ftp.lstc.com/anonymous/outgoing/ jday/Magallanes_et_al_2010b.pdf

Malvar LJ (1998) Review of static and dynamic properties of steel reinforcing bars. Materials Journal 95(5): 609-616.

Malvar LJ and Crawford JE (1998a) Dynamic increase factors for concrete. In: Proceedings of the twentyeighth DDESB seminar, Orlando, FL, August.

Malvar LJ and Ross CA (1998b) Review of strain rate effects for concrete in tension. Materials Journal 95(6): 735-739.

Malvar LJ, Crawford JE, Wesevich JW, et al. (1997) A plasticity concrete material model for DYNA3D. International Journal of Impact Engineering 19(9-10): 847-873.

Mays G and Smith PD (1995) Blast Effects on Buildings: Design of Buildings to Optimize Resistance to Blast Loading. London: Thomas Telford Ltd.

Millard S, Molyneauxb TCK, Barnett SJ, et al. (2010) Dynamic enhancement of blast-resistant ultra high performance fibre-reinforced concrete under flexural and shear loading. International Journal of Impact Engineering 37(4): 405-413.

Ngo T, Mendis P and Krauthammer T (2007) Behavior of ultrahigh-strength prestressed concrete panels subjected to blast loading. Journal of Structural Engineering 133(11): 1582-1590.

Qian S and Li VC (2007) Simplified inverse method for determining the tensile strain capacity of strain hardening cementitious composites. Journal of Advanced Concrete Technology 5(2): 235-246.

Rilem T (2002) 162-TDF: test and design methods for steel fibre reinforced concrete. Materials and Structures 35: 579-582.

Schwer LE and Murray YD (1994) A three-invariant smooth cap model with mixed hardening. International Journal for Numerical and Analytical Methods in Geomechanics 18(10): 657-688.

Shi Y, Hao H and Li ZX (2008) Numerical derivation of pressure-impulse diagrams for prediction of RC column damage to blast loads. International Journal of Impact Engineering 35(11): 1213-1227.

Stang H and Li VC (2004) Classification of fiber reinforced cementitious materials for structural applications. In: Proceedings of the BEFIB, Varenna, September 2004, pp 197-218.

Stengel T (2009) Effect of surface roughness on the steel fibre bonding in ultra high performance concrete (UHPC). In: Bittnar Z, Bartos PJM, Němeček J, et al. (eds) Nanotechnology in Construction 3. Berlin: Springer, pp. 371-376. 
$\mathrm{Su} \mathrm{Y}$, Li J, Wu C, et al. (2016a) Effects of steel fibres on dynamic strength of UHPC. Construction and Building Materials 114: 708-718.

$\mathrm{Su} \mathrm{Y,} \mathrm{Li} \mathrm{J,} \mathrm{Wu} \mathrm{C,} \mathrm{et} \mathrm{al.} \mathrm{(2016b)} \mathrm{Influences} \mathrm{of} \mathrm{nano-particles} \mathrm{on} \mathrm{dynamic} \mathrm{strength} \mathrm{of} \mathrm{ultra-high} \mathrm{performance}$ concrete. Composites Part B: Engineering 91: 595-609.

$\mathrm{Su}$ Y, Wu C, Li J, et al. (2017) Development of novel ultra-high performance concrete: from material to structure. Construction and Building Materials 135: 517-528.

Walter R and Olesen JF (2005) Method for Determination of Tensile Properties of Engineered Cementitious Composites (ECC). Vancouver, BC, Canada: The University of British Columbia.

Weidner AM (2013) Dynamic Properties of Concrete and Fiber Reinforced Concrete at Room and Elevated Temperatures. Salt Lake City, UT: The University of Utah.

Wille K and Naaman AE (2013) Effect of ultra-high-performance concrete on pullout behavior of highstrength brass-coated straight steel fibers. ACI Materials Journal 110(4): 451-462.

Wille K, Kim DJ and Naaman AE (2011) Strain-hardening UHP-FRC with low fiber contents. Materials and Structures 44(3): 583-598.

Wu C, Oehlersa DJ, Rebentrost M, et al. (2009) Blast testing of ultra-high performance fibre and FRPretrofitted concrete slabs. Engineering Structures 31(9): 2060-2069.

$\mathrm{Xu} \mathrm{J}, \mathrm{Wu} \mathrm{C}$, Xiang H, et al. (2016) Behaviour of ultra high performance fibre reinforced concrete columns subjected to blast loading. Engineering Structures 118: 97-107.

Yi NH, Kim JJ, Han TS, et al. (2012) Blast-resistant characteristics of ultra-high strength concrete and reactive powder concrete. Construction and Building Materials 28(1): 694-707.

Yoo DY, Lee JH and Yoon YS (2013) Effect of fiber content on mechanical and fracture properties of ultra high performance fiber reinforced cementitious composites. Composite Structures 106: 742-753.

Zhang F, Wu C, Zhao XL, et al. (2016) Experimental and numerical study of blast resistance of square CFDST columns with steel-fibre reinforced concrete. Engineering Structures 149: 50-63. 